\title{
Effects of Carbon Corrosion on Mass Transfer Losses in Proton Exchange
}

\section{Membrane Fuel Cells}

\author{
Xu Zhang ${ }^{\mathrm{a}}$, Yupeng Yang ${ }^{\mathrm{a}}$, Liejin Guo ${ }^{\mathrm{a},{ }^{*}}$, Hongtan Liu ${ }^{\mathrm{b}, *}$ \\ ${ }^{a}$ International Research Center for Renewable Energy, State Key Laboratory of \\ Multiphase Flow in Power Engineering, Xi'an Jiaotong University, Xi'an, Shaanxi \\ 710049, P R China \\ ${ }^{\mathrm{b}}$ Clean Energy Research Institute, Department of Mechanical and Aerospace \\ Engineering, University of Miami, Coral Gables, FL 33124, USA
}

Xu Zhang

Tel.: +86298266 5591; fax: +862982669033

Email address: zhangxuxjtu@gmail.com (X. Zhang)

Yupeng Yang

Tel.: +86298266 5591; fax: +862982669033

Email address: yyp1990@stu.xjtu.edu.cn (Y. Yang)

*Liejin Guo

Corresponding author: Tel.: +86298266 3895; fax: +862982669033.

Email address: 1j-guo@mail.xjtu.edu.cn (L.Guo).

*Hongtan Liu

Corresponding author: Tel.: +1 305284 2019; fax: +1 3052842580 .

E-mail address: hliu@miami.edu (H. Liu). 


\section{Abstract}

Carbon corrosion in proton exchange membrane fuel cells (PEMFC) causes not only kinetic degradation, but also damages to electrode microstructure and hydrophobicity, which can lead to increases in mass transport resistance. While much attention has been paid to catalyst degradation and kinetic losses, the increases in mass transfer loss is also a very serious problem and thus it is the focus of this work. To induce carbon corrosion, accelerated stress test (AST) by holding the cell potential at $1.4 \mathrm{~V}$ is used. The AST procedure is interrupted periodically to record cell performance after each period of AST at three different current densities. Experiment results show that at low current density, the decrease in cell voltage is linear with time of AST, but the rate in cell voltage decrease accelerates after some period of AST at medium and high current densities. It is hypothesized that such an accelerated voltage decrease is from the increase in mass transfer loss due to water flooding in the MEA. Further experiments with either reduced inlet air humidification or reduce air flow rate confirm that water flooding in the MEA is the cause for the sharp decline in cell voltages. A phenomenon that the cell voltage increases, or the rate in cell voltage reduction decreases as cell degradation progresses is repeatedly observed. It is determined that such a phenomenon is mainly caused by the enhanced phase-change-induced flow (PCI) due to the higher heat generation rate in a more severely degraded cell. The experimental results also provide some insights on how to optimize operating conditions for degraded fuel cells.

Keywords: PEMFC, fuel cells, carbon corrosion, mass transfer loss, water transport, accelerated stress test 


\section{Introduction}

Carbon corrosion in a proton exchange membrane fuel cell (PEMFC) has been recognized as a serious cause in reducing fuel cell durability and much effort has been devoted to the understanding the mechanisms of carbon corrosion and its detrimental consequences [1, 2]Error! Bookmark not defined.. The mechanisms for reversecurrent have been particularly clarified, and it is known that reverse current may occur during frequent start-ups and shut-downs, reactant starvations, reactant mal-distribution or improper water management [3, 4]. Extensive studies have been conducted on the resulting catalyst degradation and kinetic losses [5, 6], the interactions between carbon support and platinum catalyst [7, 8], hydrophobicity loss of carbon surface [9-11], porous microstructure and morphology damages in the catalyst layer (CL) [12-14] and the interface between the micro-porous layer (MPL) and the gas diffusion layer (GDL) [15].

Corrosion of carbon support in CL causes platinum nanoparticle detachment, migration, electronic isolation or agglomeration, leading to severe reduction in electrochemical area (ECA) [6, 16]. Besides, consumption of carbon support is also reported to decrease the thickness of $\mathrm{CL}[5,7]$ and even to result in microstructure collapse in the CL [7, 13] . Hydrophilic oxide functional groups formed on carbon surface make the carbon surface less hydrophobic $[10,11]$ and alter the morphology and interfaces in CL $[17,18]$. Carbon corrosion was also reported to occur in GDL and MPL $[15,19]$. Chen et al [20] studied the carbon corrosion in GDL with an ex situ experiment and found severe structure changes and hydrophobicity loss. Ha et al [15] conducted an in situ experiment to study carbon corrosion in GDL with MPL. The penetration part of MPL into GDL pores was found to be the most vulnerable. 
Emergence of empty space or gap at the MPL penetration part was observed due to carbon corrosion.

Due to the significant damages of carbon corrosion on electrode porous microstructure, alternation of material physicochemical properties and composition in $\mathrm{CL}$ and GDL/MPL, water transport in pores and further mass transfer loss must be affected. It is known that water transport plays a vital role in determining fuel cell performance. Water balance in PEMFC should ensure a good trade-off between flooding avoidance and membrane hydration to reduce both ohmic and mass transfer losses [21]. Hence studies of water transport and water management both in CL and GDL/MPL always draw special attentions. The mechanisms for water transport in multi-scale porous layer, especially the influence of material properties, compositions, porosity, thickness, fabrication method and operating parameters on water transport both in CL and GDL/MPL have been studied extensively $[22,23]$. The porous structure $[24,25]$, the hydrophobicity [26, 27] and interfaces between components [28, 29], which are confirmed to be key factors affecting water transport, are all susceptible to carbon corrosion. However, the relationships between carbon corrosion and water transport and further with mass transfer losses in PEMFC are still unclear. Liu et al [14] measured the limiting current density in a PEMFC with local hydrogen starvation, and sharp current density drop was observed at the starvation area where the carbon corrosion was severe. Park et al [18] found that the mass transfer limitation increased due to carbon corrosion. Fairweather et al [30] studied the effect of carbon corrosion on through-plane water transport under different conditions. Pore structure deterioration, drying out effect of the heat generation in corroded cell, and hydrophilic property of the oxidized carbon surface, each differently influences through-plane water transport. 
Wood et al [31] proposed a hybridized method to separate the mass transfer overpotential in the cathode GDL and CL during a long term PEMFC operation. However, so far the change of mass transfer losses caused by carbon corrosion remained inconclusive. The variation of the water transport in porous layers, including CL and GDL/MPL, introduces great uncertainties to water management and control strategy for PEMFCs [30, 32].

The objective of present work is to study the effects of carbon corrosion on mass transfer losses in PEMFC. The mechanisms of carbon corrosion on mass transfer losses are further studied by using either lower air humidification or lower air flow rate. The mechanisms are further studied through the hysteresis phenomenon observed during the voltage sweeping procedures.

\section{Experimental}

\subsection{Experimental setup}

A single PEMFC with an active membrane electrode assembly (MEA) area of $16 \mathrm{~cm}^{2}$ is used in the experimental studies. Nafion ${ }^{\circledR} 212$ based catalyst coated membrane (CCM) (Shanghai Pearl Hydrogen Power Source, China) with a catalyst loading of $0.4 \mathrm{mg} \mathrm{cm}^{-2}$ are used. Two identical pieces of carbon paper (Toray 060, Toray Industries. Inc., Japan) with micro porous layer (MPL) are used at the anode and cathode. Graphite collector plates with machined serpentine flow fields at both sides (co-flow) are used. The width of gas channel and rib is $2 \mathrm{~mm}$ and the depth of gas channel is $1 \mathrm{~mm}$. Compression of the single cell is implemented with fuel cell hardware (Fuel Cell Technologies Inc., USA) with heaters and thermocouples to control operating temperature. Figure 1 is a schematic of the experimental fuel cell. 
The experimental system consists of the single fuel cell, a fuel cell test station (FCTS-16, Fuel Cell Technologies. Inc., USA), a Potentiosat/Galvanostat (HCP803, Bio-Logic. Inc., France). Operating parameters, such as cell temperature, reactant gas flow rates, gas humidification and back pressure, can be precisely controlled. The Potentiosat/Galvanostat is used to control cell voltage and current, and conduct electrochemical characterization, including polarization curves and electrochemical impedance spectroscopy (EIS).

\subsection{Performance characterization}

Prior to each set of experiment, the cell is preconditioned at $343 \mathrm{~K}$ with fully humidified hydrogen and air at $168 \mathrm{sccm}$ (corresponding to stoichiometry of 3 at current density of $500 \mathrm{~mA} \mathrm{~cm}^{-2}$ ) and $560 \mathrm{sccm}$ (corresponding to stoichiometry of 4 at current density of $500 \mathrm{~mA} \mathrm{~cm}^{-2}$ ), respectively. The cell voltage is decreased every 5 minute at $0.1 \mathrm{~V} / \mathrm{step}$ between OCV and $0.2 \mathrm{~V}$ until a stable performance has been reached. After the initiation procedure, the cell is considered to be at the beginning of life (BOL) and cell voltages are recorded at three different controlling current densities, i.e. $150 \mathrm{~mA} \mathrm{~cm}{ }^{-2}$, $300 \mathrm{~mA} \mathrm{~cm}^{-2}$, and $500 \mathrm{~mA} \mathrm{~cm}{ }^{-2}$. After the BOL characterization, an AST procedure is conducted. A relative high potential, $1.4 \mathrm{~V}$ in this study, is applied to the cell and held for 3 or 6 hours. During the AST procedure, anode is supplied with $100 \%$ humidified hydrogen and a flow rate of $200 \mathrm{sccm}$ and the cathode is supplied with $100 \%$ humidified nitrogen and a flow rate of $200 \mathrm{sccm}$. The cell temperature is maintained at $343 \mathrm{~K}$. The AST is stopped at $3 \mathrm{~h}, 6 \mathrm{~h}, 9 \mathrm{~h}$ and $15 \mathrm{~h}$ respectively, followed by a recovery procedure [33]. In the recovery procedure, the cell voltage is cycled between OCV and $0.2 \mathrm{~V}$ with step of $0.1 \mathrm{~V}$ for several times. The recovery procedure lasts until 
the cell performance has no apparent change, indicating complete recovery of the reversible portion of the degradation. Then the cell performance characterizations are conducted at the same three different controlling current densities as given above. Current density is maintained constant for at least 10 minutes and the stable corresponding voltages are recorded. After the performance characterization, the cell is subjected to another AST period. This cycle of AST, recovery procedure, performance characterization, is repeated until the end of 15 hours of AST.

A triangle voltage sweep experiment is performed to record the hysteresis behavior of the cell. The cell voltage is swept between OCV and $0.2 \mathrm{~V}$ with a rate of $1 \mathrm{mV} \mathrm{s}^{-1}$. As the sweeping rate is sufficiently slow, the cell can be considered to be in quasi-steady state. Hence, the hysteresis behaviors between the voltage descending period and the voltage ascending period can be obtained. The cell temperature is always maintained at $343 \mathrm{~K}$ at the bipolar plate by a temperature control module fixed in the test station. The back pressures at both anode and cathode are set at 1 atmosphere absolute. The relative humidity $\left(\mathrm{RH}_{\mathrm{a}}\right)$ and flow rate of hydrogen at anode are kept at $100 \%$ and $168 \mathrm{sccm}$, respectively. The cathode is purged with air with relativity humidity $\left(\mathrm{RH}_{\mathrm{c}}\right)$ at $100 \%$ and flow rate at $560 \mathrm{sccm}$. In order to study the mass transfer variation, the cell performance is also characterized under following two conditions, respectively. First, air $\mathrm{RH}_{\mathrm{c}}$ is reduced to $50 \%$ with all the other operating parameter unchanged; and second, the air flow rate is reduced to $267 \mathrm{sccm}$ (corresponding to stoichiometry of 2 at $500 \mathrm{~mA} \mathrm{~cm}{ }^{-2}$ ) while keeping all other parameters unchanged. In order to guarantee the consistency of the experimental conditions, the cell is equilibrated at $\mathrm{OCV}$ for at least $10 \mathrm{~min}$ before each test run. 


\section{Results and Discussions}

\subsection{Effects on mass transfer losses}

The changes of cell voltage caused by AST at three different controlling current densities are shown in Fig.2. Air at the cathode is supplied with a flow rate of $560 \mathrm{sccm}$ and $\mathrm{RH}_{\mathrm{c}}$ of $100 \%$. It is seen that the voltage decreases slightly from BOL to AST $3 \mathrm{~h}$ at the low current density of $150 \mathrm{~mA} \mathrm{~cm}^{-2}$. After AST $3 \mathrm{~h}$, the voltage decrease rate at low current density is linear with time, indicating a linear kinetic degradation. At a medium current density of $300 \mathrm{~mA} \mathrm{~cm} \mathrm{~cm}^{-2}$ the rate of voltage reduction increases and is particularly high from AST $3 \mathrm{~h}$ to AST $9 \mathrm{~h}$. It is interesting to note that the rate of voltage reduction decreases from AST $9 \mathrm{~h}$ to AST $15 \mathrm{~h}$. At a high current density of 500 $\mathrm{mA} \mathrm{cm}{ }^{-2}$, the decrease of cell voltage becomes very rapid, and the pre-set current density of $500 \mathrm{~mA} \mathrm{~cm}^{-2}$ cannot be achieved after AST 15h. It can be seen that the decreases of voltage at medium and large current densities are not linear with time. Rapid voltage declines at both medium and high current densities are believed to be the result of both severe kinetic degradations and mass transfer losses. The large deviation from the linear rate is believed to be caused by mass transfer losses. The decrease of hydrophobicity due to the oxidized carbon surface is believed to increase liquid water saturations in the porous GDL and CL. At $500 \mathrm{~mA} \mathrm{~cm}^{-2}$ the phenomenon of decreased voltage reduction rate can also be seen from AST $6 \mathrm{~h}$ to AST $9 \mathrm{~h}$. This phenomenon suggests that effect of carbon corrosion on mass transfer involves different mechanisms.

\subsection{Mechanisms of mass transfer losses due to carbon corrosion}

In order to further study the mechanisms carbon corrosion on mass transfer losses, two sets of additional experiments have been conducted. In the first set, air with lower 
humidification, $50 \% \mathrm{RH}_{\mathrm{c}}$ is used instead of the fully humidified air $\left(100 \% \mathrm{RH}_{\mathrm{c}}\right)$. The hypothesis is that if the greater rate of decrease in cell voltage at medium and high current densities are caused by water flooding of the MEA, a much lower air humidity will significantly reduce the effect of flooding, if not eliminate it [34]. In the second set of experiments, a much lower air flow rate is used. The hypothesis is that liquid water removal will be reduced at a lower air flow rate [35] and the rate of decrease in cell voltage would be even greater.

Figure 3 presents the results when air is supplied at $50 \% \mathrm{RH}_{\mathrm{c}}$ and at the same flow rate as before. It can be seen in Fig. 3 that the initial voltage is slight lower at $50 \%$ air $\mathrm{RH}_{\mathrm{c}}$ due to lower membrane hydration. However, the decreases of voltage at the three controlling current densities are much slower and the curves are smoother compared to those at $100 \%$ air $\mathrm{RH}_{\mathrm{c}}$. When the inlet air is at $50 \% \mathrm{RH}_{\mathrm{c}}$, much of cell is free from liquid water. Even with reduced hydrophobicity due to carbon corrosion, the MEA cannot be flooded and thus the sharp decrease in cell voltage does not occur. The decrease in cell performance is dominated by kinetic and ohmic losses. These results confirm the hypothesis that the sharp drops in cell voltages are caused by water flooding in the MEA due to carbon corrosion.

Figure 4 shows the results when air $\mathrm{RH}_{\mathrm{c}}$ is $100 \%$ and flow rate is reduced to 267 sccm. It is clear that at lower air flow rate, when liquid water removal capability by air convection is significantly lower, the decrease in cell voltage become more dramatic, especially at high current densities. After 3 h AST, the high current density of $500 \mathrm{~mA}$ $\mathrm{cm}^{-2}$ cannot even be achieved - the cell is severely flooded. With a lower air flow rate, liquid water cannot be effectively removed. When carbon corrosion occurs and has caused a decrease in hydrophobicity of the pores, the cell is very prone to flooding. 
These results further confirm the hypothesis that the sharp drops in cell voltages are caused by water flooding.

As discussed above, an interesting phenomenon can be observed in Fig. 2 that the rate for voltage decrease actually decreases after certain period of AST. The same interesting phenomenon can also be observed in Fig.4, only to be drastically enlarged at low air flow rate, especially for the case at current density of $300 \mathrm{~mA} \mathrm{~cm}{ }^{-2}$. At lower air flow rate, the cell voltage decreases even more rapidly from BOL to AST $6 \mathrm{~h}$ due to flooding, and then it increases significantly from AST 6 h to AST 9 h. Since kinetic degradation increases linearly with time, the increase in cell voltage must be caused by complicated mass transfer in the fuel cell.

In order to study the mechanisms of the complicated mass transfer losses due to carbon corrosion, a closer examination at different effects is needed. It is relatively straightforward to understand the accelerated mass transfer losses due to carbon corrosion. As explained above, since carbon corrosion causes formation of hydrophilic oxide groups on carbon surface $[10,11]$, the MEA is more prone to flooding, thus mass transfer loss can increase drastically. Besides, carbon corrosion can also lead to severe porosity drop or microstructure damages in CL and GDL [7, 13], even without flooding, the effective diffusivity of the MEA can also decrease and lead to increase of mass transfer losses.

The repeatedly observed phenomenon of either reduced mass transfer loss or decreased rate in mass transfer loss after certain period of AST is contra-intuitive. As a fuel cell is subjected to a longer period of AST, obviously it is impossible for carbon corrosion to reverse its course rather than getting worse. However, when a more degraded cell is forced to operate at the same current density as for a less degraded one, 
the cells voltage is significantly lower, resulting in a higher heat generation rate. The higher heat generation rate leads to a higher temperature in the catalyst layer, resulting in enhanced phase change induced flow (PCI). The PCI can plays a vital role in liquid water removal when carbon corrosion happens in PEMFC, as elucidated by Fairweather et al. [30] and Weber et al. [36]. This PCI enhancement of liquid water removal is particularly pronounced at high current densities due to the greater heat generation rate. This is reason that this phenomenon is mainly observed at medium and high current densities. Besides, at lower air flow rate, the capabilities of the air in removing liquid water and heat are reduced and as a results, the effect of PCI is more pronounced, causing the voltage after AST 9h to exceed that after AST 6h (Fig.4 current density at $300 \mathrm{~mA} \mathrm{~cm}^{-2}$ ).

\subsection{Hysteresis behavior}

The hysteresis behavior of a PEM fuel cell during voltage sweep experiments has been intensively studied by Ziegler et al [37-39] and used as an indicator of liquid water content in the MEA [40, 41]. In such an experiment, during the voltage descending period, cell current increases and the rate of water production increases. If water cannot be removed quickly enough, the MEA can be flooded. Then during the voltage ascending period, the cell current density will be lower than that during the voltage ascending period. On the other hand, in the high voltage region, the hysteresis behavior is usually reversed due to lower ohmic resistance during voltage ascending period. The hysteresis behaviors can be used to quantify liquid water saturation level in the MEA and its water removal capability. 
Voltage sweeping experiments have been conducted at the conditions of air $\mathrm{RH}_{\mathrm{c}}$ at $100 \%$ and flow rate $560 \mathrm{sccm}$, same conditions at those for Fig. 2. The results of polarization curves are shown in Fig. 5. It is seen that for the new cell, i.e. at BOL, there is hardly any hysteresis between the voltage ascending and descending polarization curves. Since the inlet air is $100 \%$ humidified and large amount of water is generated, excess water must be present in the MEA. Such results indicate that the cell has very good water removal capability. However, from AST 3h on, the current densities during voltage descending periods are always higher than those during voltage ascending periods, indicating liquid water accumulation and flooding in the MAE. These results further confirm that carbon corrosion can significantly reduce MEA's water removal capability and make it more prone to flooding, as discussed earlier.

It is interesting to observe from Fig. 5 that the amount of hysteresis decreases as the cell is further degraded from AST $6 \mathrm{~h}$ to AST $9 \mathrm{~h}$. Comparing the two cases at the same current density, after AST $9 \mathrm{~h}$ the difference in cell voltage is significantly smaller than that after AST $6 \mathrm{~h}$. These results further corroborate with the analysis that phase change induced flow due to the higher heat generation rate is important. Comparing the two cases at the same voltage, it is obvious that the more degraded cell has much lower current density and thus much lower water generation rate. Even though it may have lower water removal capability, there simply is not much water to remove.

The results of hysteresis behavior at reduced air humidification, 50\% $\mathrm{RH}_{\mathrm{c}}$ and the same flow rate are shown in Fig.6. The operating conditions are the same as those shown in Fig.3. The results show that for all the cases, the current densities during the voltage ascending periods are higher than those during the voltage descending periods. With lower humidification at the inlet, the membrane is not fully hydrated and the cell 
has higher ohmic resistance. As the cell current density increases, more water is generated and the membrane becomes better hydrated, resulting in higher current densities. As discussed earlier on the results in Fig.3, under a relatively dry operating condition, even the cell is degraded and carbon corrosion occurs, there is not enough water to cause flooding of the MEA. These results further confirm that the sharp drop in cell voltage observed in Fig. 2 is due to water flooding caused by carbon corrosion. The results shown in Fig.6 also provide an important insight on optimizing operating conditions for degraded fuel cells - a relatively lower inlet gas humidification is actually better for fuel cells with some carbon corrosion.

Figure 7 presents the hysteresis behaviors with reduced air flow rate at $267 \mathrm{sccm}$ and other parameters unchanged. The operating conditions are the same as those in Fig.4. It can be seen that at the BOL, there is no hysteresis caused by liquid water accumulation, but the amount of hysteresis is very large after the cell is degraded, indicating severe flooding. It can also be observed from Fig. 7 that some sudden drop in current densities occurred during voltage descending period, indicating the occurrence of severe flooding [37]. The phenomenon of reduced hysteresis, indicating reduced water flooding as degradation continues can also be observed from AST $3 \mathrm{~h}$ to AST $9 \mathrm{~h}$. These results also indicate that a higher air flow rate is better for a fuel cell with carbon corrosion.

\section{Conclusions}

The effects of carbon corrosion on mass transfer losses in a PEMFC are studied using an AST procedure. After an initial conditioning process at the beginning of life and the reversible degradation recovery procedure [33] following each AST, cell voltages are 
recorded at three different controlling current densities. Additional experiments have also been conducted under either lower inlet air humidification or lower air flow rate. The hysteresis behaviors of the PEMFC under different degraded conditions are also measured. Based on the experimental results, following conclusions can be made:

- Carbon corrosion in a degraded fuel cell can cause large mass transfer losses.

- Large mass transfer loss in degraded fuel cell is due to water flooding in MEA caused by carbon corrosion.

- There exists a phenomenon of either reduced mass transfer loss or decreased rate in mass transfer loss after certain period of AST.

- The recovery of mass transfer losses is caused by enhanced phase change induced flow resulting from higher heat generation rate in a more severely degraded cell.

- The severe water flooding problem caused by carbon corrosion can be eliminated or mitigated by operating at lower inlet humidity and/or higher air flow rates.

\section{Acknowledgements}

The financial supports from the National Science Foundation of China for Creative Research Groups (No. 51121092) are gratefully acknowledged. 


\section{References:}

[1] Yousfi-Steiner N, Mocoteguy P, Candusso D, Hissel D. A review on polymer electrolyte membrane fuel cell catalyst degradation and starvation issues: Causes, consequences and diagnostic for mitigation. J Power Sources. 2009;194:130-45.

[2] Zhang YL, Chen SG, Wang Y, Ding W, Wu R, Li L, et al. Study of the degradation mechanisms of carbon-supported platinum fuel cells catalyst via different accelerated stress test. J Power Sources. 2015;273:62-9.

[3] Chen JX, Hu JW, Waldecker JR. A Comprehensive Model for Carbon Corrosion during Fuel Cell Start-Up. J Electrochem Soc. 2015;162:F878-F89.

[4] Reiser CA, Bregoli L, Patterson TW, Yi JS, Yang JDL, Perry ML, et al. A reverse-current decay mechanism for fuel cells. Electrochem Solid St. 2005;8:A273-A6.

[5] Jung GB, Chuang KY, Jao TC, Yeh CC, Lin CY. Study of high voltage applied to the membrane electrode assemblies of proton exchange membrane fuel cells as an accelerated degradation technique. Applied Energy. 2012;100:81-6.

[6] Castanheira L, Dubau L, Mermoux M, Berthome G, Caque N, Rossinot E, et al. Carbon Corrosion in Proton-Exchange Membrane Fuel Cells: From Model Experiments to Real-Life Operation in Membrane Electrode Assemblies. Acs Catalysis. 2014;4:2258-67.

[7] Yu PT, Liu ZY, Makharia R. Investigation of Carbon Corrosion Behavior and Kinetics in Proton Exchange Membrane Fuel Cell Cathode Electrodes. J Electrochem Soc. 2013;160:F645-F50.

[8] Linse N, Gubler L, Scherer GG, Wokaun A. The effect of platinum on carbon corrosion behavior in polymer electrolyte fuel cells. Electrochim Acta. 2011;56:7541-9.

[9] Oh H-S, Lim KH, Roh B, Hwang I, Kim H. Corrosion resistance and sintering effect of carbon supports in polymer electrolyte membrane fuel cells. Electrochim Acta. 2009;54:6515-21.

[10] Zhao Z, Castanheira L, Dubau L, Berthome G, Crisci A, Maillard F. Carbon corrosion and platinum nanoparticles ripening under open circuit potential conditions. J Power Sources. 2013;230:236-43.

[11] Young AP, Colbow V, Harvey D, Rogers E, Wessel S. A Semi-Empirical Two Step Carbon Corrosion Reaction Model in PEM Fuel Cells. J Electrochem Soc2013. p. F381-F8.

[12] Patterson TW, Darling RM. Damage to the cathode catalyst of a PEM fuel cell caused by localized fuel starvation. Electrochem Solid St. 2006;9:A183-A5. 
[13] Schulenburg H, Schwanitz B, Linse N, Scherer GG, Wokaun A, Krbanjevic J, et al. 3D Imaging of Catalyst Support Corrosion in Polymer Electrolyte Fuel Cells. J Phys Chem C. 2011;115:14236-43.

[14] Liu ZY, Brady BK, Carter RN, Litteer B, Budinski M, Hyun JK, et al. Characterization of carbon corrosion-induced structural damage of PEM fuel cell cathode electrodes caused by local fuel starvation. J Electrochem Soc. 2008;155:B979-B84.

[15] Ha T, Cho J, Park J, Min K, Kim HS, Lee E, et al. Experimental study on carbon corrosion of the gas diffusion layer in polymer electrolyte membrane fuel cells. Int J Hydrogen Energy. 2011;36:12436-43.

[16] Hitchcock AP, Berejnov V, Lee V, West M, Colbow V, Dutta M, et al. Carbon corrosion of proton exchange membrane fuel cell catalyst layers studied by scanning transmission X-ray microscopy. J Power Sources. 2014;266:66-78.

[17] Mashio T, Malek K, Eikerling M, Ohma A, Kanesaka H, Shinohara K. Molecular Dynamics Study of Ionomer and Water Adsorption at Carbon Support Materials. J Phys Chem C. 2010;114:13739-45.

[18] Park S, Shao YY, Viswanathan VV, Liu J, Wang Y. Non-kinetic losses caused by electrochemical carbon corrosion in PEM fuel cells. Int J Hydrogen Energy. 2012;37:8451-8.

[19] Park J, Oh H, Ha T, Lee YI, Min K. A review of the gas diffusion layer in proton exchange membrane fuel cells: Durability and degradation. Applied Energy. 2015;155:866-80.

[20] Chen GB, Zhang HM, Ma HP, Zhong HX. Electrochemical durability of gas diffusion layer under simulated proton exchange membrane fuel cell conditions. Int J Hydrogen Energy. 2009;34:8185-92.

[21] Bresciani F, Casalegno A, Varisco G, Marchesi R. Water transport into PEFC gas diffusion layer: experimental characterization of diffusion and permeation. International Journal of Energy Research. 2014;38:602-13.

[22] Yim SD, Sohn YJ, Park SH, Yoon YG, Park GG, Yang TH, et al. Fabrication of microstructure controlled cathode catalyst layers and their effect on water management in polymer electrolyte fuel cells. Electrochimica Acta. 2011;56:9064-73.

[23] Cho KT, Mench MM. Effect of material properties on evaporative water removal from polymer electrolyte fuel cell diffusion media. Journal of Power Sources. 2010;195:6748-57.

[24] Oh H, Park J, Min K, Lee E, Jyoung JY. Effects of pore size gradient in the substrate of a gas diffusion layer on the performance of a proton exchange membrane fuel cell. Applied Energy. 2015;149:186-93. 
[25] Strahl S, Husar A, Franco AA. Electrode structure effects on the performance of open-cathode proton exchange membrane fuel cells: A multiscale modeling approach. International Journal of Hydrogen Energy. 2014;39:9752-67.

[26] Zhang F-Y, Spernjak D, Prasad AK, Advani SG. In Situ Characterization of the Catalyst Layer in a Polymer Electrolyte Membrane Fuel Cell. Journal of The Electrochemical Society. 2007;154:B1152.

[27] Kitahara T, Nakajima H, Inamoto M, Morishita M. Novel hydrophilic and hydrophobic double microporous layer coated gas diffusion layer to enhance performance of polymer electrolyte fuel cells under both low and high humidity. Journal of Power Sources. 2013;234:129-38.

[28] Tabe Y, Aoyama Y, Kadowaki K, Suzuki K, Chikahisa T. Impact of micro-porous layer on liquid water distribution at the catalyst layer interface and cell performance in a polymer electrolyte membrane fuel cell. Journal of Power Sources. 2015;287:422-30.

[29] LaManna JM, Bothe JV, Zhang FY, Mench MM. Measurement of capillary pressure in fuel cell diffusion media, micro-porous layers, catalyst layers, and interfaces. Journal of Power Sources. 2014;271:180-6.

[30] Fairweather JD, Spernjak D, Weber AZ, Harvey D, Wessel S, Hussey DS, et al. Effects of Cathode Corrosion on Through-Plane Water Transport in Proton Exchange Membrane Fuel Cells. J Electrochem Soc. 2013;160:F980-F93.

[31] Wood DL, Borup RL. Estimation of Mass-Transport Overpotentials during Long-Term PEMFC Operation. J Electrochem Soc. 2010;157:B1251-B62.

[32] Ous T, Arcoumanis C. Degradation aspects of water formation and transport in Proton Exchange Membrane Fuel Cell: A review. J Power Sources. 2013;240:558-82.

[33] Zhang X, Guo LJ, Liu HT. Recovery mechanisms in proton exchange membrane fuel cells after accelerated stress tests. J Power Sources. 2015;296:327-34.

[34] Sun H, Zhang GS, Guo LJ, Dehua S, Liu HT. Effects of humidification temperatures on local current characteristics in a PEM fuel cell. Journal of Power Sources. 2007;168:400-7.

[35] Gerteisen D, Zamel N, Sadeler C, Geiger F, Ludwig V, Hebling C. Effect of operating conditions on current density distribution and high frequency resistance in a segmented PEM fuel cell. International Journal of Hydrogen Energy. 2012;37:7736-44. 
[36] Weber AZ, Borup RL, Darling RM, Das PK, Dursch TJ, Gu W, et al. A Critical Review of Modeling Transport Phenomena in Polymer-Electrolyte Fuel Cells. Journal of the Electrochemical Society. 2014;161:F1254-F99.

[37] Ziegler C, Gerteisen D. Validity of two-phase polymer electrolyte membrane fuel cell models with respect to the gas diffusion layer. Journal of Power Sources. 2009;188:184-91.

[38] Gerteisen D, Heilmann T, Ziegler C. Modeling the phenomena of dehydration and flooding of a polymer electrolyte membrane fuel cell. Journal of Power Sources. 2009;187:165-81.

[39] Ziegler C, Heilmann T, Gerteisen D. Experimental study of two-phase transients in PEMFCs. Journal of the Electrochemical Society. 2008;155:B349-B55.

[40] Shah AA, Kim GS, Sui PC, Harvey D. Transient non-isothermal model of a polymer electrolyte fuel cell. Journal of Power Sources. 2007;163:793-806.

[41] Von Dahlen S, Schneider IA. Local Flooding Phenomena in Channel and Land Areas Occurring during Dynamic Operation of a PEFC. Fuel Cells. 2012;12:1004-8. 


\section{List of Figures}

Fig. 1. Schematic of the experimental fuel cell.

Fig. 2. Cell voltages at BOL and after different periods of AST. Inlet air humidity $\mathrm{RH}_{\mathrm{c}}$ at $100 \%$ and air flow rate at $560 \mathrm{sccm}$ (corresponding to stoichiometry of 4 at current density of $500 \mathrm{~mA} \mathrm{~cm}^{-2}$ ).

Fig. 3. Cell voltages at BOL and after different periods of AST. Inlet air humidity $\mathrm{RH}_{\mathrm{c}}$ at $50 \%$ and air flow rate at $560 \mathrm{sccm}$ (corresponding to stoichiometry of 4 at current density of $500 \mathrm{~mA} \mathrm{~cm}^{-2}$ ).

Fig. 4. Cell voltages at BOL and after different periods of AST. Inlet air humidity $\mathrm{RH}_{\mathrm{c}}$ at $100 \%$ and air flow rate at $267 \mathrm{sccm}$ (corresponding to stoichiometry of 2 at current density of $500 \mathrm{~mA} \mathrm{~cm}^{-2}$ ).

Fig. 5. Hysteresis behaviors on I-V curves after different periods of AST. Air supplied at $100 \% \mathrm{RH}_{\mathrm{c}}$ and $560 \mathrm{sccm}$ (corresponding to stoichiometry of 4 at current density of $500 \mathrm{~mA} \mathrm{~cm}^{-2}$ ).

Fig. 6. Hysteresis behaviors on I-V curves after different periods of AST. Air supplied at $50 \% \mathrm{RH}_{\mathrm{c}}$ and $560 \mathrm{sccm}$ (corresponding to stoichiometry of 4 at current density of 500 $\left.\mathrm{mA} \mathrm{cm}{ }^{-2}\right)$.

Fig. 7. Hysteresis behaviors on I-V curves after different periods of AST. Air supplied at $100 \% \mathrm{RH}_{\mathrm{c}}$ and $267 \mathrm{sccm}$ (corresponding to stoichiometry of 2 at current density of $500 \mathrm{~mA} \mathrm{~cm}^{-2}$ ). 


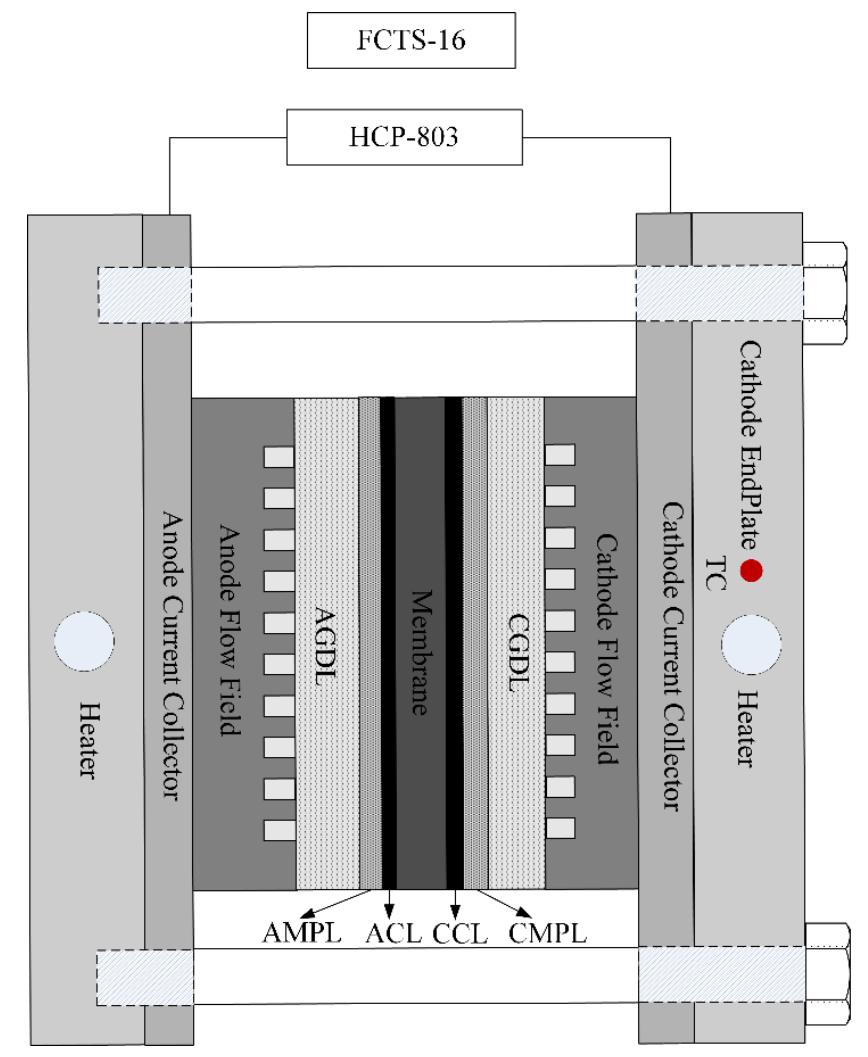

Fig. 1. Schematic of the experimental fuel cell. 


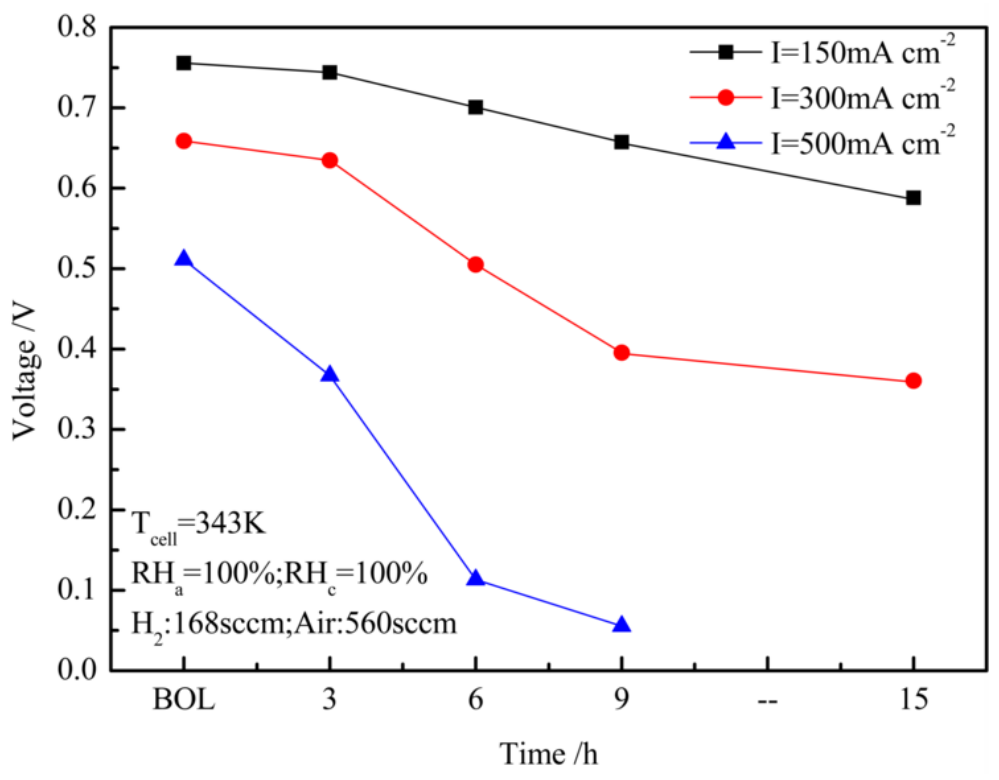

Fig. 2. Cell voltages at BOL and after different periods of AST. Inlet air humidity $\mathrm{RH}_{\mathrm{c}}$ at $100 \%$ and air flow rate at $560 \mathrm{sccm}$ (corresponding to stoichiometry of 4 at current density of $500 \mathrm{~mA} \mathrm{~cm}^{-2}$ ). 


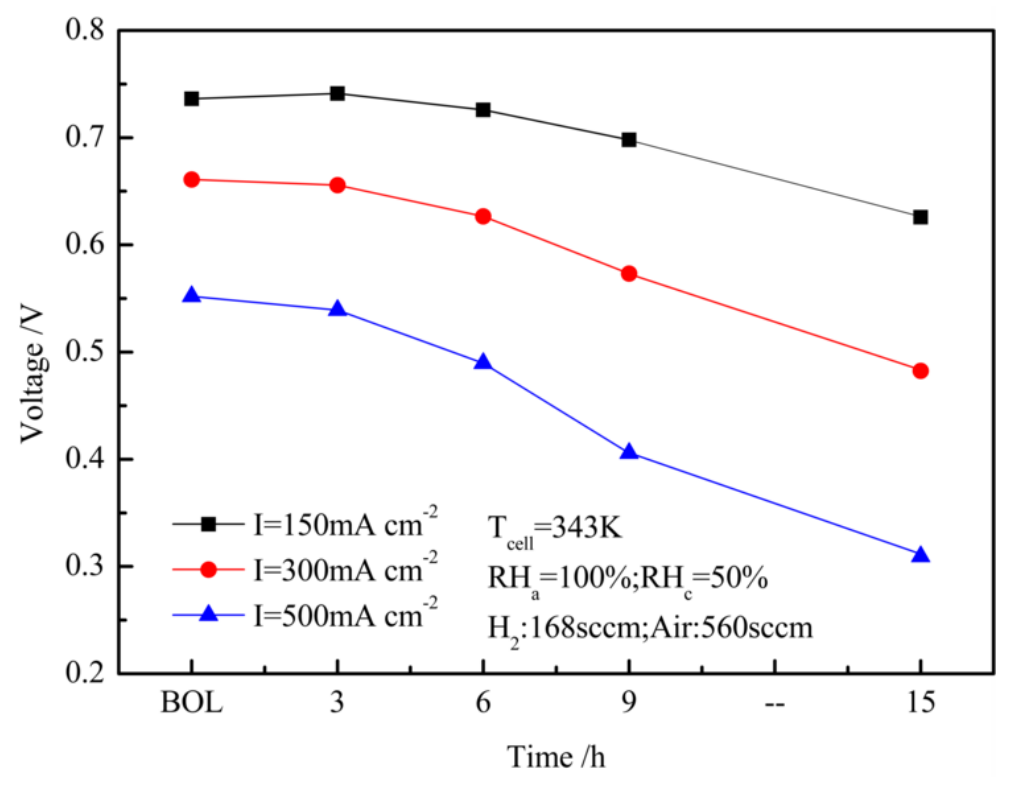

Fig. 3. Cell voltages at BOL and after different periods of AST. Inlet air humidity $\mathrm{RH}_{\mathrm{c}}$ at $50 \%$ and air flow rate at $560 \mathrm{sccm}$ (corresponding to stoichiometry of 4 at current density of $500 \mathrm{~mA} \mathrm{~cm}^{-2}$ ). 


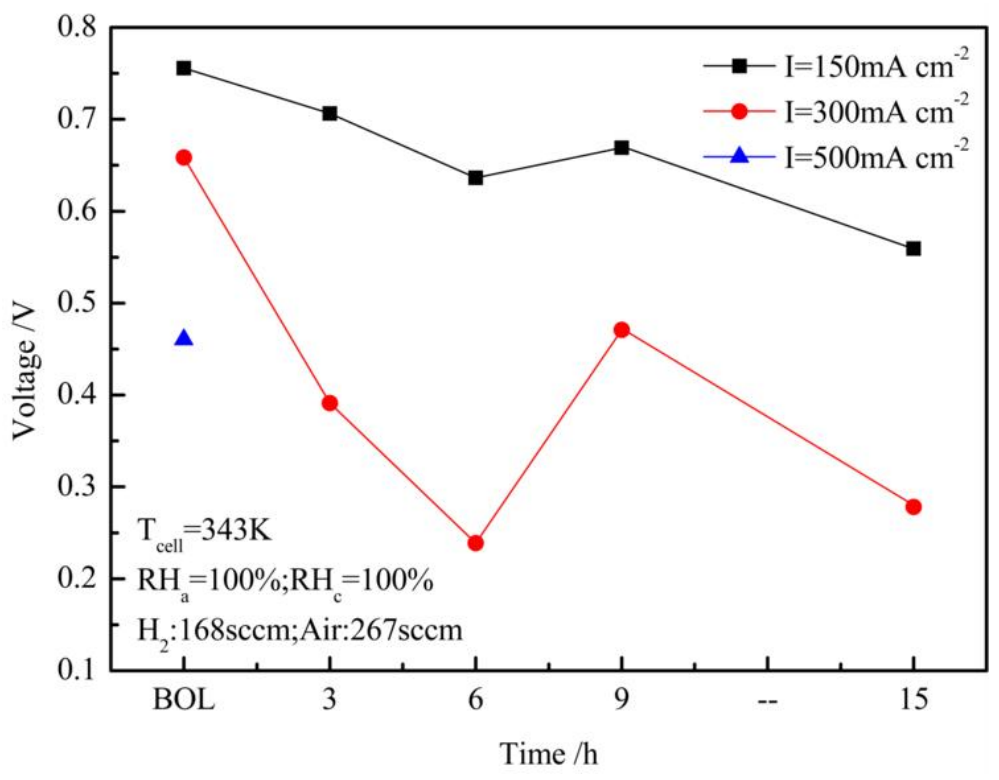

Fig. 4. Cell voltages at BOL and after different periods of AST. Inlet air humidity $\mathrm{RH}_{\mathrm{c}}$ at $100 \%$ and air flow rate at $267 \mathrm{sccm}$ (corresponding to stoichiometry of 2 at current density of $500 \mathrm{~mA} \mathrm{~cm}^{-2}$ ). 


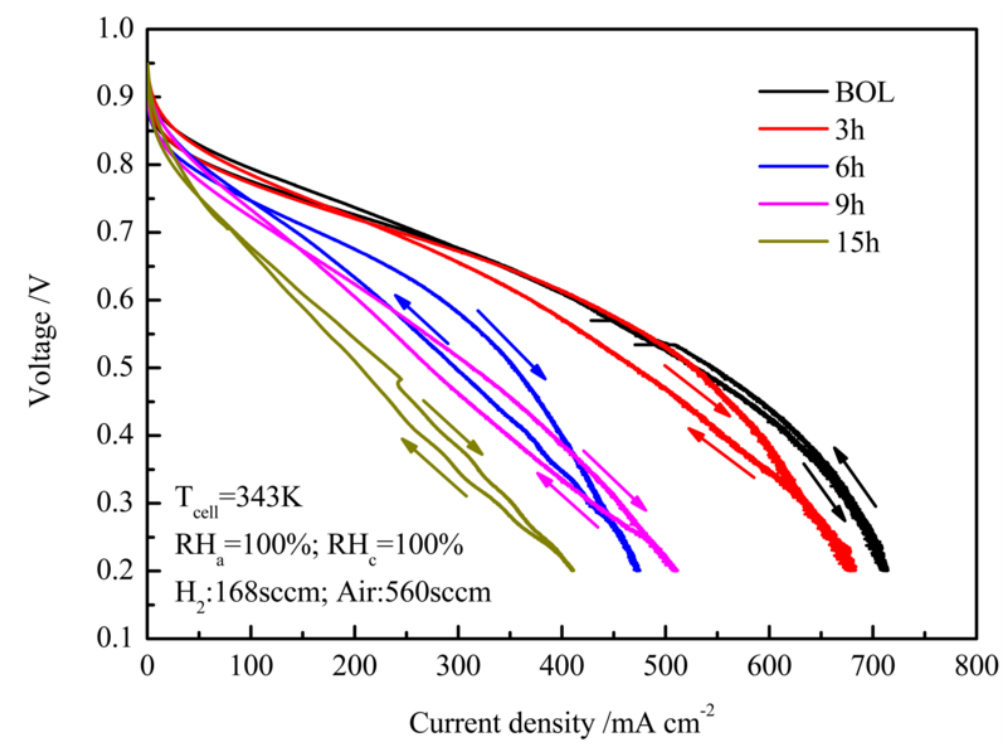

Fig. 5. Hysteresis behaviors on I-V curves after different periods of AST. Air supplied at $100 \% \mathrm{RH}_{\mathrm{c}}$ and $560 \mathrm{sccm}$ (corresponding to stoichiometry of 4 at current density of $500 \mathrm{~mA} \mathrm{~cm}^{-2}$ ). 


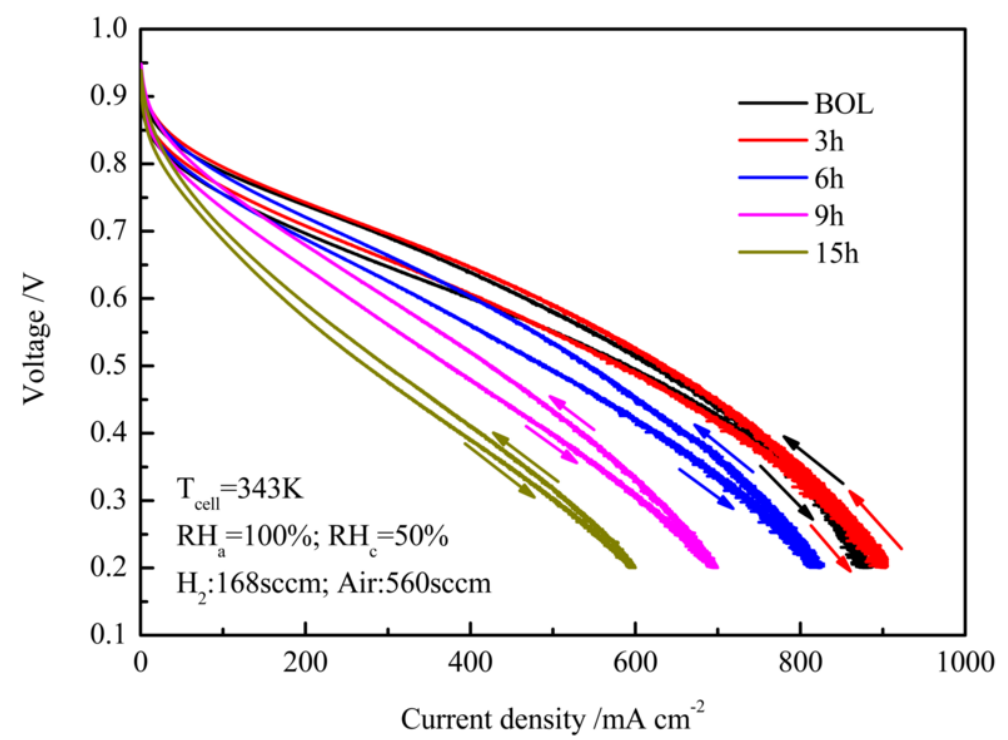

Fig. 6. Hysteresis behaviors on I-V curves after different periods of AST. Air supplied at $50 \% \mathrm{RH}_{\mathrm{c}}$ and $560 \mathrm{sccm}$ (corresponding to stoichiometry of 4 at current density of 500

$$
\left.\mathrm{mA} \mathrm{cm}{ }^{-2}\right) \text {. }
$$




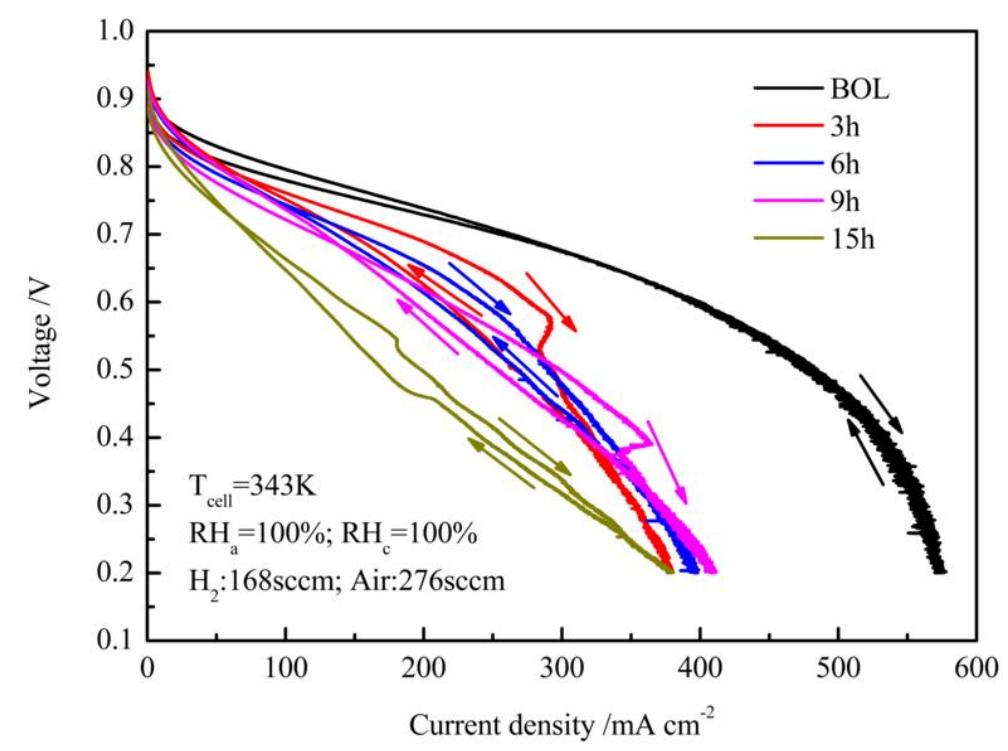

Fig. 7. Hysteresis behaviors on I-V curves after different periods of AST. Air supplied at $100 \% \mathrm{RH}_{\mathrm{c}}$ and $267 \mathrm{sccm}$ (corresponding to stoichiometry of 2 at current density of $\left.500 \mathrm{~mA} \mathrm{~cm}^{-2}\right)$. 